Published as: Labuschagne F, Molefe DM, Focke WW, van der Westhuizen I, Wright HC, Royeppen MD. Heat stabilising flexible PVC with layered double hydroxide derivatives. Polymer Degradation and Stability. 2015;113:46-54.

\title{
Heat stabilising flexible PVC with layered double hydroxide derivatives
}

FJWJ (Johan) Labuschagne ${ }^{1}$, Dan Matlhomola Molefe ${ }^{2}$, Walter W Focke ${ }^{1, *}$, Isbé van der Westhuizen $^{1}$, Harry Charles Wright ${ }^{1}$ and Mikhail David Royeppen ${ }^{1}$

\author{
${ }^{1}$ Institute of Applied Materials, Department of Chemical Engineering, University of Pretoria, Private Bag X20, Hatfield \\ 0028, South Africa \\ ${ }^{2}$ Department of Chemistry, University of Pretoria, Private Bag X20, Hatfield 0028, South Africa
}

\begin{abstract}
The layered double hydroxide $\left(\left[\mathrm{Mg}_{0.667} \mathrm{Al}_{0.333}(\mathrm{OH})_{2}\right]\left(\mathrm{CO}_{3}\right)_{0.167} \cdot m \mathrm{H}_{2} \mathrm{O}\right)(\mathrm{LDH})$ has found application as a heat stabiliser for PVC. Derivatives of this compound were synthesised using a hydrothermal method. Emulsion grade PVC was plasticised with 100 phr diisononyl phthalate and stabilised with $30 \mathrm{phr}$ of the LDH filler additives. Heat stabilities were determined at $200{ }^{\circ} \mathrm{C}$. The dynamic heat stability tests were performed on the plastisols using the torque rheometer method. Static heat stability was evaluated on the fused compounds. It was evaluated from discoloration profiles of strips exposed for various lengths of time to heat in a Metrastat oven. The time dependence of hydrogen chloride evolution was followed with a Metrohm Thermomat instrument. The conventional LDH provided the best dynamic heat stability. However, partial replacement of the magnesium with copper significantly delayed the release of volatile $\mathrm{HCl}$. If instead the replacement was done using zinc, better colour retention was achieved.
\end{abstract}

Keywords: Layered double hydroxide; poly(vinyl chloride); heat stabiliser; thermal analysis

*Corresponding author: Tel: +27 12420 3728. Fax: +27 12420 2516. E-mail address: walter.focke@ up.ac.za (W.W. Focke) 


\section{Introduction}

Hydrotalcite $\left[\mathrm{Mg}_{6} \mathrm{Al}_{2}(\mathrm{OH})_{16}\right] \mathrm{CO}_{3} .4 \mathrm{H}_{2} \mathrm{O}$ is a naturally occurring anionic clay mineral. Layered double hydroxides (LDH) $\left(\left[\mathrm{M}_{(1-x)}^{\mathrm{II}} \mathrm{M}^{\mathrm{III}}{ }_{x}(\mathrm{OH})_{2}\right]^{x+}\left(\mathrm{A}_{(x / n)}^{n-}\right) \cdot m \mathrm{H}_{2} \mathrm{O}\right)$ are synthetic analogues $[1,2]$. The structure of these compounds consists of trioctahedral metal hydroxide sheets that alternate with interlayers containing anions and water. The brucite-like sheets have a net positive charge $x$ per formula unit owing to isomorphic substitution of some of the divalent cations $\left(\mathrm{M}^{\mathrm{II}}=\mathrm{Mg}, \mathrm{Ca}, \mathrm{Zn}, \mathrm{Fe}, \mathrm{Co}, \mathrm{Ni}, \mathrm{Cu}\right.$, etc. $)$ by trivalent ones $\left(\mathrm{M}^{\mathrm{III}}=\mathrm{Al}, \mathrm{Fe}, \mathrm{Cr}\right.$, Mn, etc.). This net positive charge is balanced by an equal negative charge from the interlayer anions $\left(\mathrm{A}^{n-}=\mathrm{CO}_{3}{ }^{2-}, \mathrm{Cl}^{-}, \mathrm{NO}_{3}{ }^{-}, \mathrm{OH}^{-}\right.$, etc. $)$. Carbonate anions in $\mathrm{LDH}-\mathrm{CO}_{3}$ do not readily ion exchange owing to strong electrostatic and hydrogen-bonding interactions [3]. However, others such as nitrate, hydroxides and chloride ions are exchangeable and this facilitates incorporation of many different anions $[1,4,5]$. The number of co-intercalated (associated) water molecules $(m)$ depends on environmental conditions [6]. The stoichiometric coefficient $(x)$ can be varied over a wide range, giving rise to a large class of same structural materials $[3,7]$

Poly(vinyl chloride) (PVC) is a commodity polymer with numerous industrial and consumer applications. PVC processing is associated with many practical difficulties owing to its relatively low thermal stability [8]. Thermal degradation during processing is a common problem in polymer processing. In the case of PVC, a unique feature is the release of free hydrochloric acid. The reaction is initiated at defect sites (e.g., internal allylic chloride and tertiary chloride structural flaws). It proceeds as an autocatalytic dehydrochlorination of the PVC backbone with the liberated hydrogen chloride assuming a catalytic role [9]. The mechanism of autocatalysis involves a free-radical process that converts ordinary polymer repeat units into chloroallylic structures of low thermal stability [10]. Apart from liberating a corrosive gas, this degradation reaction also results in the formation of polyene sequences of 
$\pi$-conjugated double bonds along the polymer chain. Besides causing severe discoloration, the net effect is a loss of desirable physical and mechanical properties [8].

In practice the processing problems associated with the use of PVC are overcome through the use of heat stabiliser additives[8]. Three main heat stabiliser types are recognised, i.e. preventive, suppressive and curative heat stabilisers [11]. Preventive stabilisers substitute labile chlorine atoms for more stable groups and thus act during the initial stages of PVC thermal degradation. Suppressive stabilisers are $\mathrm{HCl}$ scavengers, and act by removing the acidic dehydrochlorination catalyst. Curative stabilisers are able to add to double bonds in the PVC backbone. Stabilisers that react with allylic chlorides are called primary stabilisers, e.g. zinc stearate, lead- and tin compounds. These reactions shorten the $\pi$-conjugated polyene sequence and thereby reduce the discoloration of degrading PVC. Furthermore they also retard the auto-acceleration process by transforming highly labile allylic chloride structures into more stable groups [11].

$\mathrm{HCl}$ generated by the degradation catalyses the chain propagation reaction. Scavenging it is a way to stop the further degradation of PVC. The diffusion of $\mathrm{HCl}$ is a slow process so that this approach cannot prevent dehydrochlorination in its early stages. However, heat stabilisers that scavenge $\mathrm{HCl}$ help to avoid autocatalytic degradation and consequently the rate of degradation is slower. These secondary stabilisers give good long term stabilisation. They include calcium stearate, lead compounds and layered double hydroxides (LDHs). Some of the most effective heat stabilisers for PVC are based on $\mathrm{Pb}, \mathrm{Cd}$ and $\mathrm{Sn}$ compounds [8]. For environmental reasons these toxic heavy metal-based complexes are being phased out. Layered double hydroxides (LDHs) are promising alternatives for lead-containing suppressive heat stabilisers owing to their intrinsically high capacity to react with $\mathrm{HCl}$ [1214]. Unlike most metallic salts, the conventional LDH is readily incorporated into the PVC resin to provide translucent articles. The thermal stabilisation action of LDH involves two 
steps. Initially, $\mathrm{HCl}$ formed during thermal dehydroclorination, displaces the carbonate interlayer anions to afford LDHs with $\mathrm{Cl}^{-}$anions in the interlayer. As further dehydrochlorination takes place, the $\mathrm{HCl}$ reacts with the clay itself, ultimately destroying its structure and forming metal chlorides, metal hydroxy-chlorides and hydrates of magnesium and aluminium [13].

The present interest is to explore ways to improve the heat stabilisation effect of LDH in PVC. This communication considers LDH modifications related to partial or full substitution of the magnesium or aluminium components of conventional LDH with other metals. The effect of these modifications on the heat stability of plasticised PVC was studied. Heat stability was evaluated by tracking the temporal progression of PVC degradation. It was quantified by following the evolution of $\mathrm{HCl}$, the development of colour due to formation of conjugated double bond sequences and the change of the apparent melt viscosity caused by crosslinking or cleavage of the polymer chain [15].

\section{Experimental}

\subsection{Materials}

$\mathrm{Al}(\mathrm{OH})_{3}$ was an industrial grade supplied by Chemical Initiatives. All other reagents used were analytical grade reagents supplied by Merck. TPC Paste Resin Co., Ltd. supplied poly(vinyl chloride) emulsion grade PG680. It was a free flowing powder with a K-value of 69. The diisononyl phthalate (DINP) plasticiser was supplied by Isegen.

\subsubsection{Synthesis of $L D H$-derivatives}

The LDH-derivatives were synthesised according to the method described by Labuschagné $e t$ al., [16]. A typical procedure for $\left[\mathrm{Mg}_{0.667} \mathrm{Al}_{0.333}(\mathrm{OH})_{2}\right]\left(\mathrm{CO}_{3}\right)_{0.167} \cdot m \mathrm{H}_{2} \mathrm{O}$, i.e., $\mathrm{MgAl}-\mathrm{LDH}$ was as follows: Light $\mathrm{MgO}$ and $\mathrm{Al}(\mathrm{OH})_{3}$ powders were mixed in the required 2:1 stoichiometric 
ratio. The powder mix was slowly added, while stirring, to one litre of distilled water in a 1.6 L Parr autoclave. The final solids concentration of the slurry was $15 \mathrm{wt}$. \%. A $60 \mathrm{~mol} \%$ excess of $\mathrm{NaHCO}_{3}$ was added to the mixture as the source for the intercalate anion. The reaction was conducted under vigorous stirring at a temperature of $180{ }^{\circ} \mathrm{C}$ and a pressure of approximately 14 bar. The autoclave was kept at this temperature and pressure for approximately $5 \mathrm{~h}$. Thereafter heating was discontinued and the reaction mixture was allowed to cool overnight while stirring. The solid product was removed from the autoclave, filtered and washed several times with distilled water to remove residual $\mathrm{NaHCO}_{3}$. Finally it was dried in an oven at $80{ }^{\circ} \mathrm{C}$ for at least $48 \mathrm{~h}$.

The substituted layered double hydroxides, i.e. LDH-derivatives, were synthesised following a similar procedure. The target was either to substitute part of the aluminium with iron(III) or part of the magnesium with copper(II) or zinc(II). For MgFeAl-LDH, $25 \mathrm{~mol} \%$ of the $\mathrm{Al}(\mathrm{OH})_{3}$ was substituted with $\mathrm{Fe}_{2} \mathrm{O}_{3}$. For MgCuAl-LDH and the MgZnAl-LDH $25 \mathrm{~mol} \%$ of the $\mathrm{MgO}$ was substituted by an equivalent molar amount of the corresponding oxide. For $\mathrm{CaAl}-\mathrm{LDH}$, all of the $\mathrm{MgO}$ was substituted with an equal molar amount of $\mathrm{CaO}$ and a proprietary carbonation procedure was employed. The compound synthesized was calcium hemicarboaluminate [17] $\left(\left[\mathrm{Ca}_{4} \mathrm{Al}_{2}(\mathrm{OH})_{12}\right]\left[\mathrm{OH}\left(\mathrm{CO}_{3}\right)_{0.5} \cdot 4 \mathrm{H}_{2} \mathrm{O}\right)\right.$. In this clay half the interlayer carbonate ions are substituted by hydroxyl ions.

\subsubsection{Surface coating of the $L D H$-derivatives}

All samples were coated with stearic acid as follows: The dried solids were milled into a fine powder using a coffee grinder. They were then suspended in $1 \mathrm{~L}$ distilled water and heated to $75^{\circ} \mathrm{C}$. The solids content of all the slurries was less than 20 wt. \%. The slurries were vigorously agitated with a Silverson disperser. Stearic acid, equivalent to $2.0 \mathrm{wt}$. \% based on the total dry uncoated solid sample, was added to the hot slurry. The suspension was stirred 
for $15 \mathrm{~min}$ at $6000 \mathrm{rpm}$. The coated powders were recovered by filtering. They were dried in a convection oven set at $60{ }^{\circ} \mathrm{C}$ and ground to a fine powder.

\subsubsection{Preparation of PVC-composites}

DINP plasticiser $(130 \mathrm{~g})$ was weighed into a $600 \mathrm{~mL}$ beaker. Next small portions of the PVC powder (up to a total of $130 \mathrm{~g}$ ) were added and mixed-in using a high-speed Anvil milkshake mixer. The dispersion was de-aerated for about 30 minutes in a Speedvac vacuum chamber. Then the LDH filler powder (39 $\mathrm{g}$ ) was incorporated. The dispersion was again de-aerated but this time for about $1 \mathrm{~h}$.

Cast PVC composite sheets were made in a three-step pressing process. The paste mixture was poured into a mould measuring $100 \mathrm{~mm} \times 100 \mathrm{~mm} \times 3.5 \pm 0.1 \mathrm{~mm}$. The mould was closed and placed in convection oven set at a temperature of $130{ }^{\circ} \mathrm{C}$ for 10 minutes. Then it was hot pressed at a pressure of $10 \mathrm{MPa}$ at $150{ }^{\circ} \mathrm{C}$ for $5 \mathrm{~min}$. The mould was then removed from the press and a heavy weight placed on the top plate. The moulding was allowed to cool down at ambient conditions before it was removed.

\subsection{Material characterisation}

\subsubsection{Particle size and BET surface area determination}

The particle size distributions were determined with a Mastersizer Hydrosizer 2000MY (Malvern Instruments, Malvern, UK). The specific surface areas of the powders were measured on a Nova 1000e BET instrument in $\mathrm{N}_{2}$ at $77 \mathrm{~K}$.

\subsubsection{Scanning Electron Microscopy (SEM)}

A small quantity of the powdered product or the LDH precursor was placed onto carbon tape on an aluminium sample holder. Excess powder was removed using a single compressed air 
blast. The samples were then coated five times with carbon under argon gas using the Polaron Equipment E5200 SEM auto-coating sputter system. The powder samples were viewed on a Zeiss Ultra plus FEG SEM scanning electron microscope.

\subsection{3. $X$-ray diffraction $(X R D)$}

X-ray diffraction analysis was performed on a PANalytical X-pert Pro powder diffractometer fitted with an X'celerator detector using Fe filtered CoKa radiation $(\lambda=0.17901 \mathrm{~nm})$. The instrument featured variable divergence and receiving slits. X'Pert High Score Plus software was used for data manipulation and phase identification.

\subsubsection{Inductively coupled plasma optical emission spectrometry (ICP-OES)}

The elemental composition of the LDH derivatives was determined with a Spectro Arcos model inductively coupled plasma optical emission spectrometer (ICP-OES). First about $0.5 \mathrm{~g}$ of the clay was dissolved in $50 \mathrm{~mL}$ Aqua Regia. After cooling down, the reaction mixture was diluted with $50 \mathrm{~mL}$ of distilled water and filtered through ashless filter paper. Before performing the ICP-OES analysis, $1 \mathrm{~mL}$ of solution was added to $99 \mathrm{~mL}$ of distilled water. The analysis was then performed, analysing for copper, magnesium, aluminium, calcium, zinc, iron and sodium. The insoluble fraction was determined by ashing the filter paper.

\subsubsection{Fourier transform infrared spectroscopy (FTIR)}

FTIR spectra were recorded on a Perkin Elmer 100 Spectrophotometer. Powder samples were pressed onto the $\mathrm{Zn} / \mathrm{Se}$ plate of a MIRacle ATR attachment. The spectra were obtained over the range $650-4000 \mathrm{~cm}^{-1}$ and represent the average of 32 scans at a resolution of $2 \mathrm{~cm}^{-1}$. 


\subsubsection{Thermogravimetric Analysis (TGA)}

Thermogravimetric analysis (TGA) was performed using the dynamic method on a Mettler Toledo A851 TGA/SDTA instrument. About 11 - $15 \mathrm{mg}$ sample was placed in an open $150 \mu \mathrm{L}$ alumina pan. Temperature was scanned from $25^{\circ} \mathrm{C}$ to $900{ }^{\circ} \mathrm{C}$ at a scan rate of $10{ }^{\circ} \mathrm{C} \min ^{-1}$ with air or nitrogen flowing at a rate of $50 \mathrm{~mL} \mathrm{~min}{ }^{-1}$.

\subsection{Heat stability assessment}

\subsubsection{Dynamic heat stability (Rheomix)}

The dynamic stability of the PVC compositions was investigated at $200{ }^{\circ} \mathrm{C}$ using the torque rheometer technique [18-20] on a Haake Polylab OS with Rheomix 600p OS Lab Mixer using roller rotors. The plastisol paste mixture (70 g) was loaded into the internal mixing chamber. The samples were processed at a rotor speed of $60 \mathrm{rpm}$ and the torque was recorded as a function of time.

\subsubsection{Metrastat thermal stability}

The static heat stability was determined in triplicate using sample strips measuring ca. $200 \mathrm{~mm} \times 20 \mathrm{~mm} \times 3.5 \pm 0.1 \mathrm{~mm}$ that were cut from the pressed sheets. A Metrastat heat stability oven was used. The strips were placed in the Metrastat trays of length $256 \mathrm{~mm}$ in random positions for each of the three runs. The machine automatically retracts the trays from the oven at a constant rate of $300 \mathrm{~mm}$ in $180 \mathrm{~min}$. The oven temperature was set at $200{ }^{\circ} \mathrm{C}$ and the air flow was $10 \mathrm{~m}^{3} \mathrm{~min}^{-1}$. After testing the strips were photographed. The change in colour along the strips was quantified using imaging software and the change in the grey scale is reported as a function of oven time. 


\subsubsection{Thermomat thermostability}

The thermostability of the PVC compounds was evaluated on a Metrohm 895 Professional PVC Thermomat according to ISO 182 Part 3. The method is based on the fact that PVC releases $\mathrm{HCl}$ when it decomposes at high temperatures. The evolved hydrochloric acid is flushed with a stream of nitrogen gas and passed through a measuring vessel where it is absorbed in purified water. The progress of the decomposition is tracked by measuring the change in the conductivity of this water. Performance is quantified in terms of either the induction time (i.e. the time that is required to reach the break point in the conductivity curve) or a stability time, i.e. the time until a conductivity difference of $50 \mu \mathrm{S} \mathrm{cm}^{-1}$ is reached. The PVC compound sample amount tested was $0.50 \pm 0.05 \mathrm{~g}$. The samples were cut into small pieces less than $1 \mathrm{~mm}$ in size. The stability was determined at $200{ }^{\circ} \mathrm{C}$. Nitrogen flow was controlled at $7 \mathrm{~L} \mathrm{~h}^{-1}$ and $50 \mathrm{~mL}$ deionised water was used to trap the $\mathrm{HCl}$.

Table 1. LDH particle sizes and BET surface area

\begin{tabular}{lcccc}
\hline & BET surface area & \multicolumn{3}{c}{ Particle size, $\boldsymbol{\mu m}$} \\
Sample & $\mathrm{m}^{2} \mathrm{~g}^{-1}$ & $\mathrm{D}_{10}$ & $\mathrm{D}_{50}$ & $\mathrm{D}_{90}$ \\
\hline MgAl-LDH & 18.3 & $0.68 \pm 0.00$ & $3.08 \pm 0.03$ & $13.10 \pm 0.26$ \\
MgZnAl-LDH & 12.4 & $0.67 \pm 0.01$ & $2.30 \pm 0.11$ & $13.93 \pm 1.36$ \\
$\mathrm{MgCuAl}-\mathrm{LDH}$ & 13.3 & $0.62 \pm 0.00$ & $2.00 \pm 0.09$ & $9.84 \pm 1.61$ \\
$\mathrm{MgFeAl}-\mathrm{LDH}$ & 9.83 & $0.61 \pm 0.01$ & $1.87 \pm 0.02$ & $4.03 \pm 0.06$ \\
$\mathrm{CaAl}-\mathrm{LDH}$ & 5.44 & $1.94 \pm 0.04$ & $6.25 \pm 0.12$ & $18.43 \pm 0.12$ \\
\hline
\end{tabular}

\section{Results}

\subsection{LDH Particle size and BET surface area}

Table 1 reports the particle sizes and the BET specific surface areas for the LDH-derivatives. The median $\left(\mathrm{D}_{50}\right)$ particle size varied from $1.9 \mu \mathrm{m}$ to $6.25 \mu \mathrm{m}$. BET surface was highest for $\operatorname{MgAl}-\mathrm{LDH}\left(18.3 \mathrm{~m}^{2} \mathrm{~g}^{-1}\right)$ and lowest for CaAl-LDH $\left(5.44 \mathrm{~m}^{2} \mathrm{~g}^{-1}\right)$. 


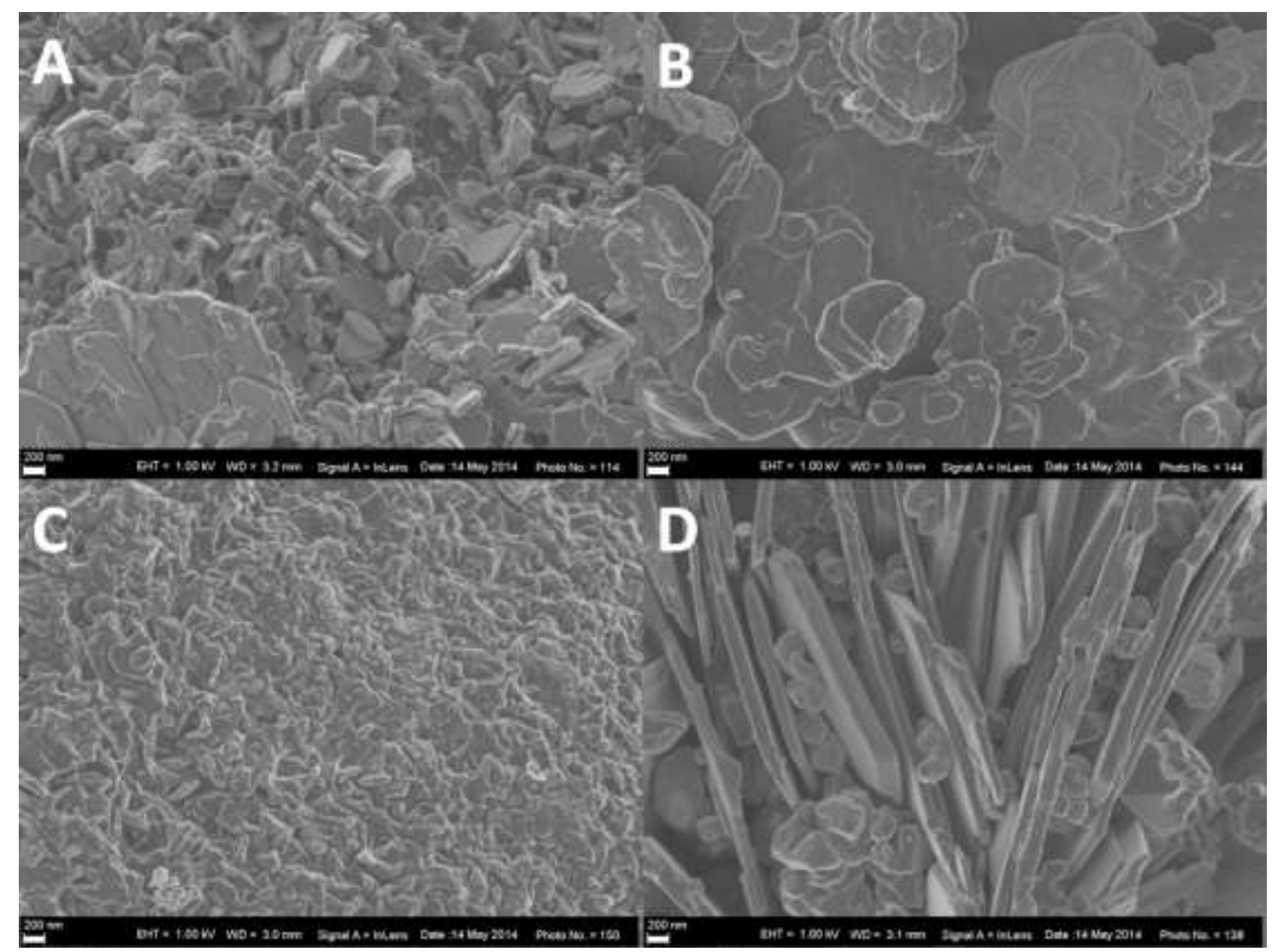

Figure 1. SEM micrographs of (A) MgZnAl-LDH; (B) MgFeAl-LDH; (C) MgCuAl-LDH, and (D) CaAl-LDH. The size bar indicates a length of $200 \mathrm{~nm}$.

\subsection{Scanning electron microscopy (SEM)}

Figure 1 shows FEG SEM micrographs of some LDH-derivative powders. The individual powder particles are made up of highly agglomerated flake-shaped crystals. The primary flakes were smallest for MgCuAl-LDH and largest for CaAl-LDH. The micrograph for the latter actually shows an edge-on view whereas the other micrographs show a top view.

\subsection{X-ray diffraction (XRD)}

The XRD patterns shown in Figure 2 feature reflections characteristic of LDHs [3]. The reflections at $2 \theta=13.474^{\circ}$ and $2 \theta=27.125^{\circ}$ in the XRD diffractogram for $\mathrm{MgAl}-\mathrm{LDH}$ are consistent with a brucite layer basal spacing of $0.761 \mathrm{~nm}$. The d-spacing values for the other 
compounds are listed in Table 2. It was slightly larger $(0.768 \mathrm{~nm})$ for the MgFeAl-LDH and slightly lower $(0.755 \mathrm{~nm})$ for CaAl-LDH than the value for MgAl-LDH $(0.761 \mathrm{~nm})$ but consistent with literature reports $[17,21,22]$. The sharp nature of the reflections points to a high crystallinity of the corresponding powders.

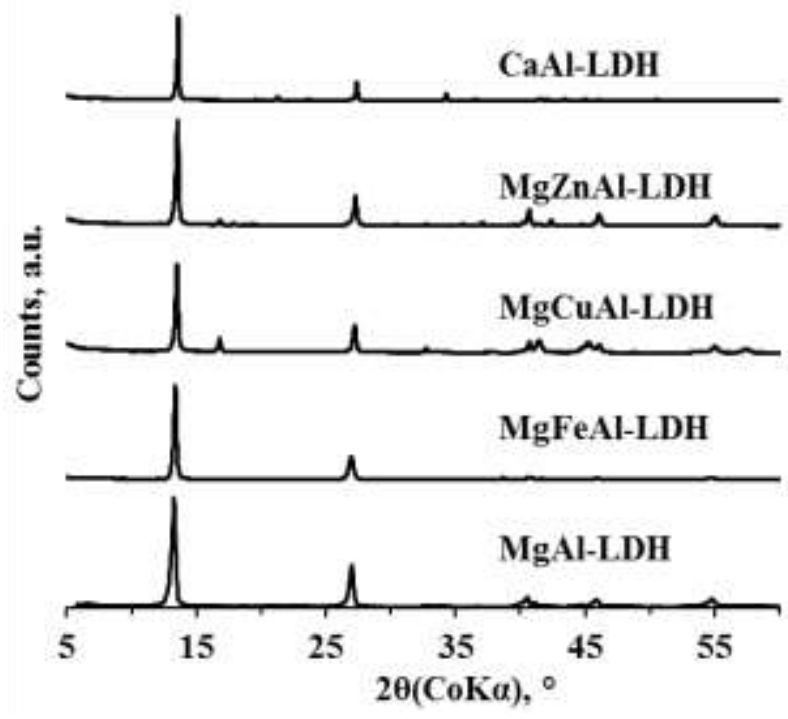

Figure 2. X-ray diffraction patterns for the various LDH derivatives

\subsection{Inductively coupled plasma optical emission spectrometry (ICP-OES)}

Table 2 reports the ICP-OES chemical composition results in terms of the general formula: $\left[\mathrm{Mg}_{2+\alpha} \mathrm{Al}_{1-\alpha}(\mathrm{OH})_{6}\right]\left(\mathrm{CO}_{3}\right)_{(1-\alpha) / 2} \cdot x \mathrm{H}_{2} \mathrm{O}$. The apparent $\alpha$ value varied from $0.08(\mathrm{MgZnAl}-\mathrm{LDH})$ to $0.28(\mathrm{CaAl}-\mathrm{LDH})$.

Table 2. LDH derivatives: Apparent elemental composition calculated from ICP-OES, TGA residue at $900{ }^{\circ} \mathrm{C}$ and d-spacing from XRD results.

\begin{tabular}{llcc}
\hline Sample & Apparent composition & Residue, \% & d-spacing, $\mathbf{n m}$ \\
\hline $\mathrm{MgAl}-\mathrm{LDH}$ & {$\left[\mathrm{Mg}_{2.092} \mathrm{Al}_{0.908}(\mathrm{OH})_{6}\right]\left(\mathrm{CO}_{3}\right)_{0.454}$} & 57.0 & 0.761 \\
$\mathrm{MgCuAl}-\mathrm{LDH}$ & {$\left[\mathrm{Mg}_{1.570} \mathrm{Cu}_{0.597} \mathrm{Al}_{0.833}(\mathrm{OH})_{6}\right]\left(\mathrm{CO}_{3}\right)_{0.417}$} & 65.6 & 0.761 \\
$\mathrm{MgZnAl}-\mathrm{LDH}$ & {$\left[\mathrm{Mg}_{1.527} \mathrm{Zn}_{0.554} \mathrm{Al}_{0.918}(\mathrm{OH})_{6}\right]\left(\mathrm{CO}_{3}\right)_{0.459}$} & 61.9 & 0.758 \\
$\mathrm{MgFeAl}-\mathrm{LDH}$ & {$\left[\mathrm{Mg}_{2.062} \mathrm{Fe}_{0.198} \mathrm{Al}_{0.740}(\mathrm{OH})_{6}\right]\left(\mathrm{CO}_{3}\right)_{0.370}$} & 56.3 & 0.768 \\
$\mathrm{CaAl}-\mathrm{LDH}$ & {$\left[\mathrm{Ca}_{2.275} \mathrm{Al}_{0.725}(\mathrm{OH})_{6}\right]\left((\mathrm{OH})_{2} \mathrm{CO}_{3}\right)_{0.182}$} & 59.2 & 0.755 \\
\hline
\end{tabular}




\subsection{Fourier transform infrared spectroscopy (FTIR)}

Figure 3 shows that all the FTIR spectra, except the one for CaAl-LDH, were very similar.

The presence of the stearic acid coating is evident from the two small peaks observed between $2993 \mathrm{~cm}^{-1}$ and $2961 \mathrm{~cm}^{-1}$ for CaAl-LDH, MgZnAl-LDH, MgCuAl-LDH and $\mathrm{MgFeAl}-\mathrm{LDH}$ respectively. The broad band that is observed at ca. $3470 \mathrm{~cm}^{-1}$ is attributed to -OH stretching vibrations in the octahedral layer and the free and hydrogen bonded water molecules present in the interlayer. The strong sharp peaks near $1366 \mathrm{~cm}^{-1}$ are due to the $\mathrm{CO}_{3}{ }^{2-} v_{3}$ antisymmetric vibrations. The CaAl-LDH shows two strong peaks here, suggesting the presence of two different environments for carbonate ions.

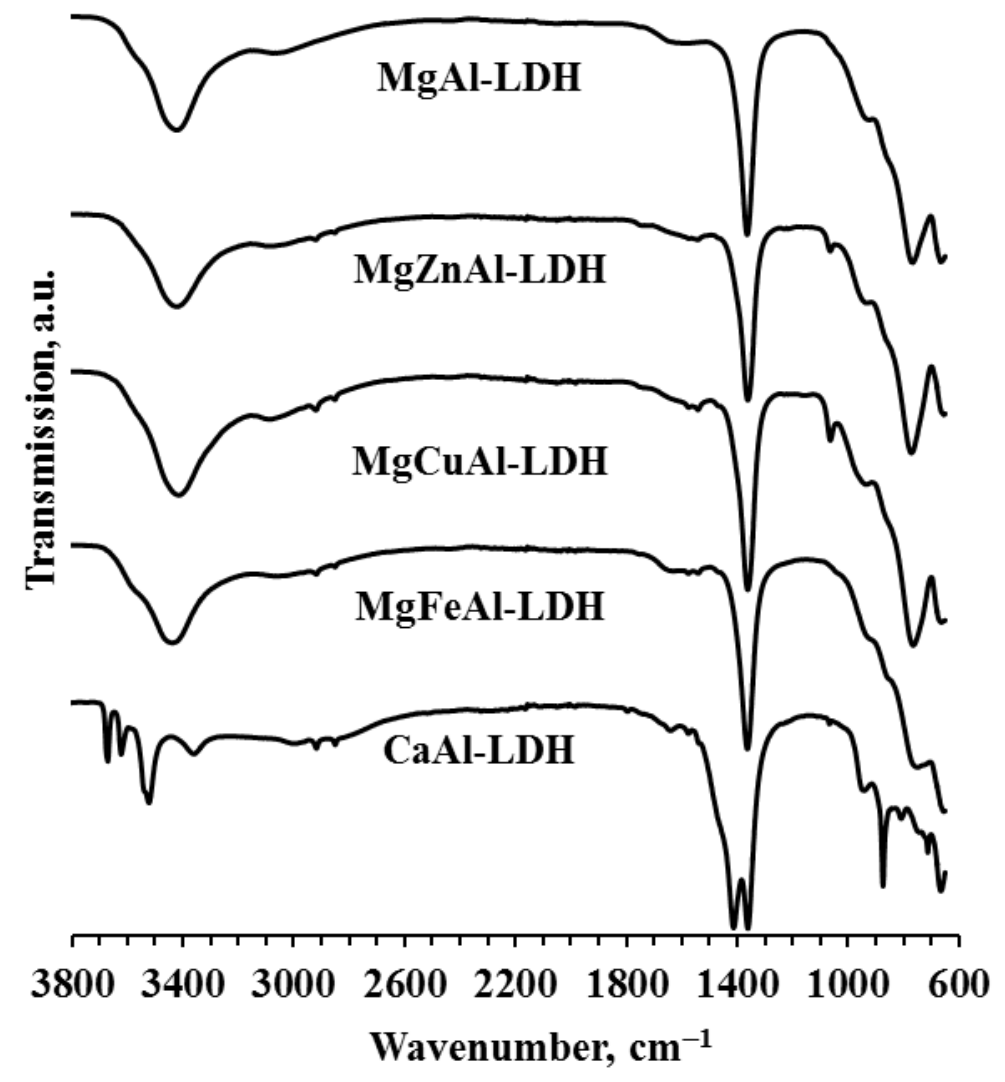

Figure 3. FTIR spectra of the various LDH derivatives 


\subsection{Thermogravimetric analysis of the LDH derivatives (TGA)}

Figure 4 summarises the TGA mass loss curves for various LDH samples as obtained in an air atmosphere. All the derivatives showed the three distinct mass loss steps expected for LDH during thermal decomposition.[23, 24] They correspond to dehydration, dehydroxylation and finally the removal of the interlayer carbonate anion. The first step is usually the loss of physisorbed and interlayer water, which commences at about $50{ }^{\circ} \mathrm{C}$ and is complete by $150{ }^{\circ} \mathrm{C}[25]$. Mass loss commenced earlier and was initially more pronounced for CaAl-LDH. It lost about $12 \%$ mass by $190{ }^{\circ} \mathrm{C}$. However, between $460{ }^{\circ} \mathrm{C}$ and $700{ }^{\circ} \mathrm{C}$ the cumulative mass loss was less than that found for the other LDH derivatives. Above the latter temperature, CaAl-LDH showed mass loss behaviour reminiscent of that expected for calcium carbonate. CaAl-LDH showed a total mass loss of $41 \%$ at $900{ }^{\circ} \mathrm{C}$. The initial mass loss for MgAl-LDH, MgZnAl-LDH, MgCuAl-LDH and MgFeAl-LDH were quite similar. However, compared to the other compounds, the TGA mass loss curve of MgCuAl-LDH appeared shifted to higher temperatures. The first mass loss event commenced at around 130 ${ }^{\circ} \mathrm{C}$ and was complete by about $250{ }^{\circ} \mathrm{C}$ showing a mass loss of ca. $12 \%$. The second mass loss event is more or less complete by $350^{\circ} \mathrm{C}$ at which point the mass loss had reached about $30 \%$. Mass loss was effectively complete by about $700{ }^{\circ} \mathrm{C}$. The residues, recorded at $900{ }^{\circ} \mathrm{C}$, are listed in Table 2. 


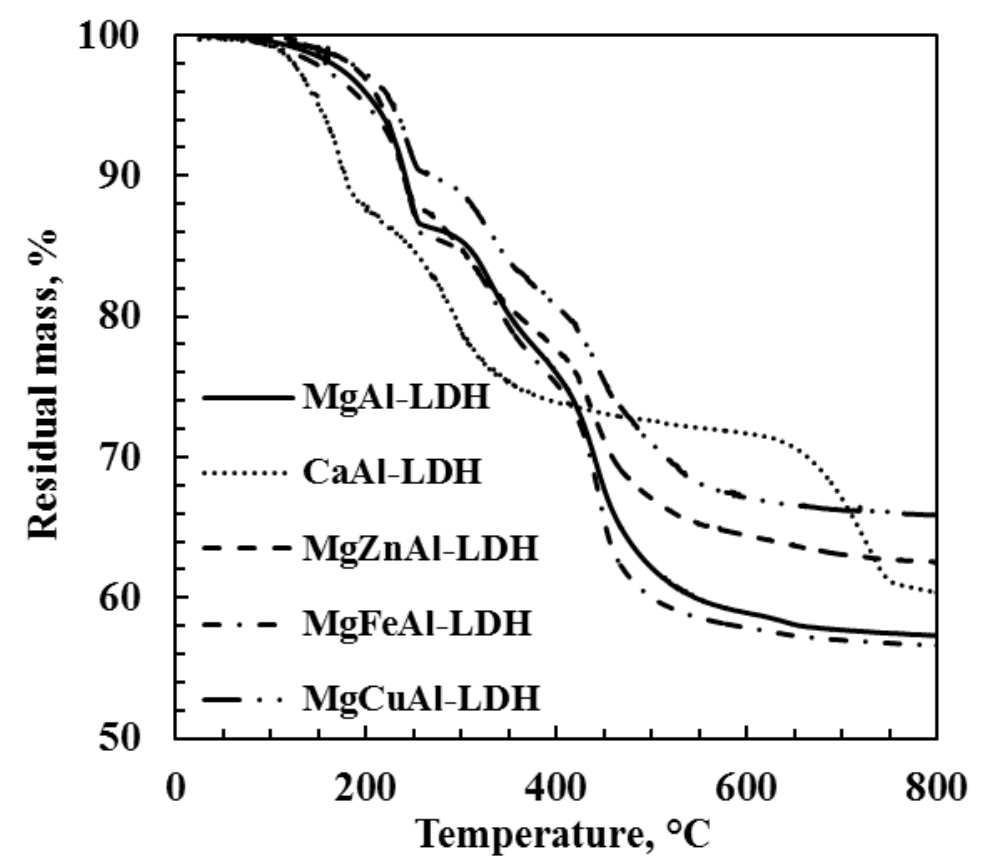

Figure 4. TGA traces in air for the LDH derivatives. Temperature was scanned from $25{ }^{\circ} \mathrm{C}$ to $900{ }^{\circ} \mathrm{C}$ at a scan rate of $10{ }^{\circ} \mathrm{C} \mathrm{min}-1$ with air flowing at a rate of $50 \mathrm{~mL} \mathrm{~min}^{-1}$.

\subsection{Heat stability of the PVC composites}

During the primary stage of degradation, discoloration of the PVC is observed. It is caused by the formation of conjugated polyene sequences of double bonds along the polymer chain. These defects are highly reactive and they undergo secondary reactions that lead to crosslinking or cleavage of the polymer chains [15]. Thus the progression of PVC degradation may be quantified by the following three approaches: (i) The evolution of $\mathrm{HCl}$; (ii) The development of colour due to formation of conjugated double bond sequences, and (iii) the changing of physical properties such as the melt viscosity due to crosslinking or cleavage of the polymer chain [15]. The Thermomat method tracks $\mathrm{HCl}$ evolution from a small sample of stabilised PVC. This method favours additives that preferentially react with $\mathrm{HCl}$ such that it begins to evolve only when the additives are completely consumed. Torque rheometer tests that simulate industrial processing conditions have the advantage that they measure the degradation under dynamic conditions. However, they react to changes in 
material consistency which is more sensitive to crosslinking or cleavage of the polymer chains. The viscosity changes are caused by the secondary degradation processes that commence relatively late in comparison to the primary PVC degradation (observed as discolouration). According to Bacaloglu and Stewen [15] by the time the viscosity starts to change, the PVC material has already been degraded to such an extent that it can no longer be used because of important appearance and mechanical property alterations. They conclude that discoloration monitoring offers the most sensitive procedure for following the PVC degradation. Owing to their very high molecular absorptivity in the visible region, conjugated polyenes with seven and more double bonds can be observed even for a degree of degradation as low as $5 \mathrm{ppm}$ of the monomer units [15].

The thermogravimetric analysis performed on the PVC compounds provided basic information on the intrinsic heat stability of the PVC compounds. Apart from the TGA, three additional heat stability tests were performed. Two were static tests and one a dynamic test. These test differed with respect to the nature of the atmosphere, the sample size and the parameter (as well as its trigger level) used to define the failure point. The Thermomat and TGA tests were performed in a nitrogen atmosphere while oxygen was present in the Metrostat and dynamic Rheomix experiments. The presence of oxygen is known to affect the rate of degradation in torque rheometer-like tests [18].

The large charge size employed in the Rheomix tests made it possible to retain a considerable amount of the evolved $\mathrm{HCl}$. The presence of higher concentrations of dissolved $\mathrm{HCl}$ affects the rate of degradation because it catalyses the dehydrochlorination reactions. In the TGA and Thermomat experiments the sample size was quite small while thin sheets were used in the Metrostat experiments. The higher surface to volume ratios, the shorter diffusion paths and the use of gas streams to sweep away the evolved gaseous degradation products clearly should affect their concentration in the samples themselves. Finally, the parameter chosen, as 
well as its trigger level, to define the end point was different in each case. Owing to these dissimilarities it should not be surprising that the heat stability ranking of the various samples was not the same in all these tests.

\subsubsection{TGA of the LDH-PVC composites}

Figure 5 shows TGA traces for the LDH-PVC compounds recorded in a nitrogen atmosphere. The flexible PVC apparently suffers two major mass loss stages. The first commences at $240{ }^{\circ} \mathrm{C}$, reaches a maximum rate at $315^{\circ} \mathrm{C}$ and ends at $370{ }^{\circ} \mathrm{C}$. At this point the residue is 20.7 wt. \%. The second stage starts as $420{ }^{\circ} \mathrm{C}$, reaches a maximum rate at $467^{\circ} \mathrm{C}$ and ends at $510{ }^{\circ} \mathrm{C}$ with a residue of $7.0 \mathrm{wt} . \%$ remaining. However, the derivative curves (DTG not shown) show multiple peaks in the mass loss stage. The initial mass losses are due a combination of PVC degradation (mainly dehydrochlorination) events and volatilisation of the plasticiser. The second stage is attributed to pyrolysis reactions that ultimately lead to a carbonaceous char residue ( 4.3 wt. $\%$ at $\left.900{ }^{\circ} \mathrm{C}\right)$. The shape of the mass loss curves for the LDH-PVC composites mirror those of PVC. The mass loss onset temperatures are virtually identical but mass loss occurs over a narrower temperature range. The residue after each stage is greater than found for the neat PVC. The ranking for initial mass loss rate, from fastest to slowest, for the additives at peak decomposition is:

$$
\text { MgZnAl-LDH }>>\text { MgFeAl-LDH }>\text { MgCuAl-LDH }>\text { CaAl-LDH } \approx \text { MgAl-LDH }
$$




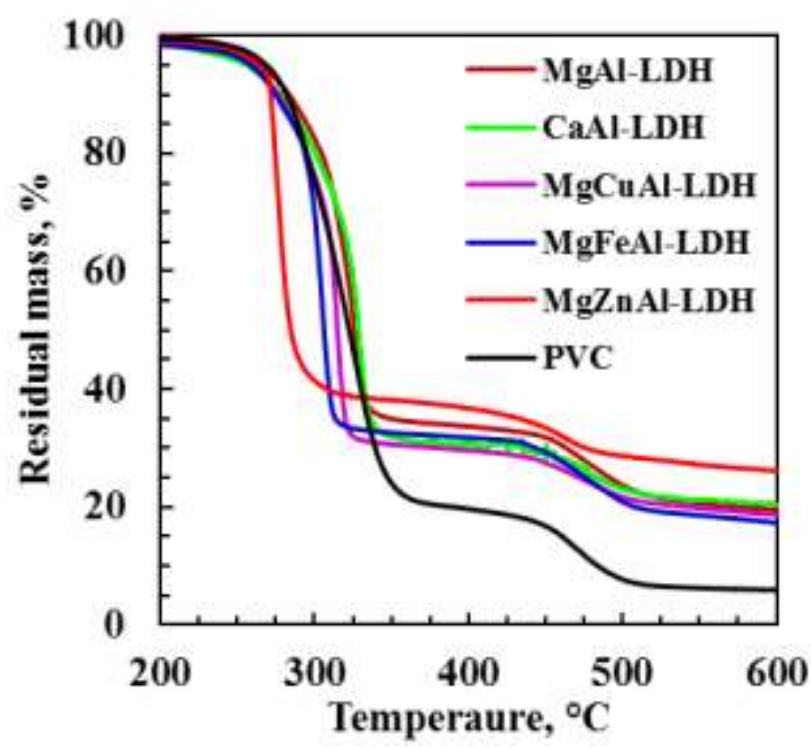

Figure 5. TGA traces in air for the PVC-LDH composites. Temperature was scanned from $25{ }^{\circ} \mathrm{C}$ to $900{ }^{\circ} \mathrm{C}$ at a scan rate of $10{ }^{\circ} \mathrm{C} \mathrm{min}^{-1}$ with nitrogen flowing at a rate of $50 \mathrm{~mL} \mathrm{~min}^{-1}$.

The MgZnAl-LDH, in particular, significantly accelerated the mass loss during the first stage. The initial decomposition yields $\mathrm{ZnCl}_{2}$ which autocatalytically accelerates the dehydrochlorination reaction according to the mechanism reported by Levchik and Weil [26]. This is also known as zinc poisoning in industry. The higher char yield is also attributed to catalytic effects that favour crosslinking and aromatisation reactions at the expense of cracking reactions that yield volatiles.

\subsubsection{Dynamic heat stability test (Rheomix)}

Representative torque $v s$. time curves are shown in Figure 6. The characteristics of the torque $v s$. time curves can be explained as follows: The high mixer chamber wall temperature and the friction imparted by the mixer blades cause rapid fusion of the plastisol into a high consistency viscous mass. This results in the very rapid rise to a peak value in the torque. As the temperature of the mix increases, the melt viscosity decreases and thus the torque decreases to a low plateau value. Over time as the material degradation proceeds, the molar mass increases because of crosslinking processes and the torque rises again. Initially the 
torque rises moderately but eventually the increase becomes much more pronounced. In the torque rheometer test the thermal stability is usually associated with the time necessary to reach the fast torque increase after the gelation process. Ideally it is measured as the time for the appearance of the inflection point in the torque-time curve. Even though these different stages of the torque curves were clearly evident in each measurement, the transitions between them were continuous.

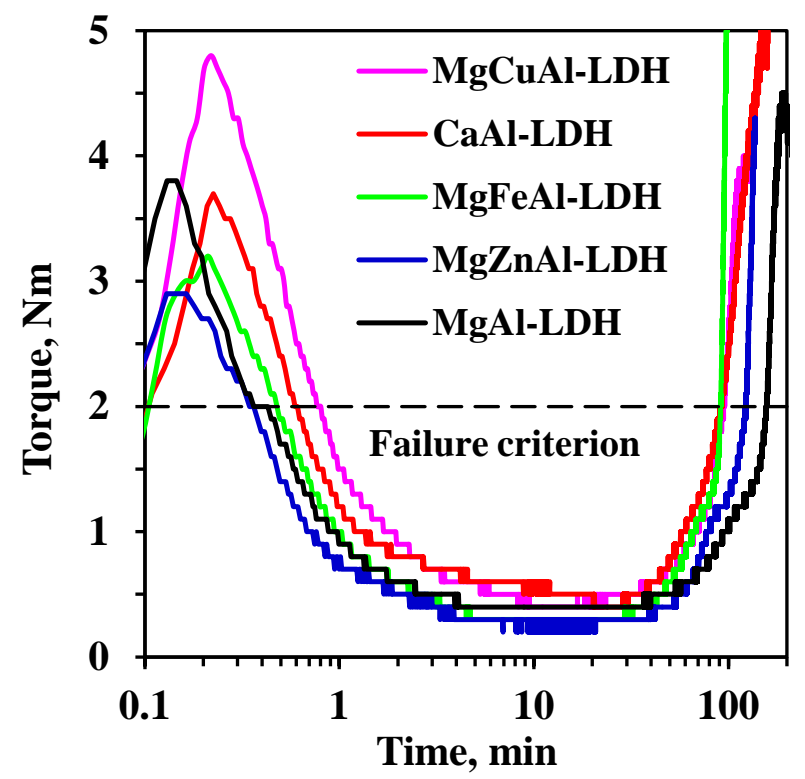

Figure 6. Representative torque $v s$. time curves obtained with the Rheomix. The rotor speed was $60 \mathrm{rpm}$ and the mixing chamber temperature was set at $200^{\circ} \mathrm{C}$.

Furthermore, the curves showed considerable superimposed noise and it was not possible to determine unequivocally the location of an inflection point. Therefore the time to reach a torque of $2 \mathrm{~N}$ was arbitrarily chosen as the heat stability measure. It is indicated by the broken horizontal line in Figure 6. The corresponding dynamic heat stability times are shown in Figure 10. The ranking of the additives from fastest to slowest degrading was as follows: MgFeAl-LDH $\approx \mathrm{CaAl}-\mathrm{LDH}>\mathrm{MgCuAl}-\mathrm{LDH}>\mathrm{MgZnAl-LDH}>>\mathrm{MgAl}-\mathrm{LDH}$ 


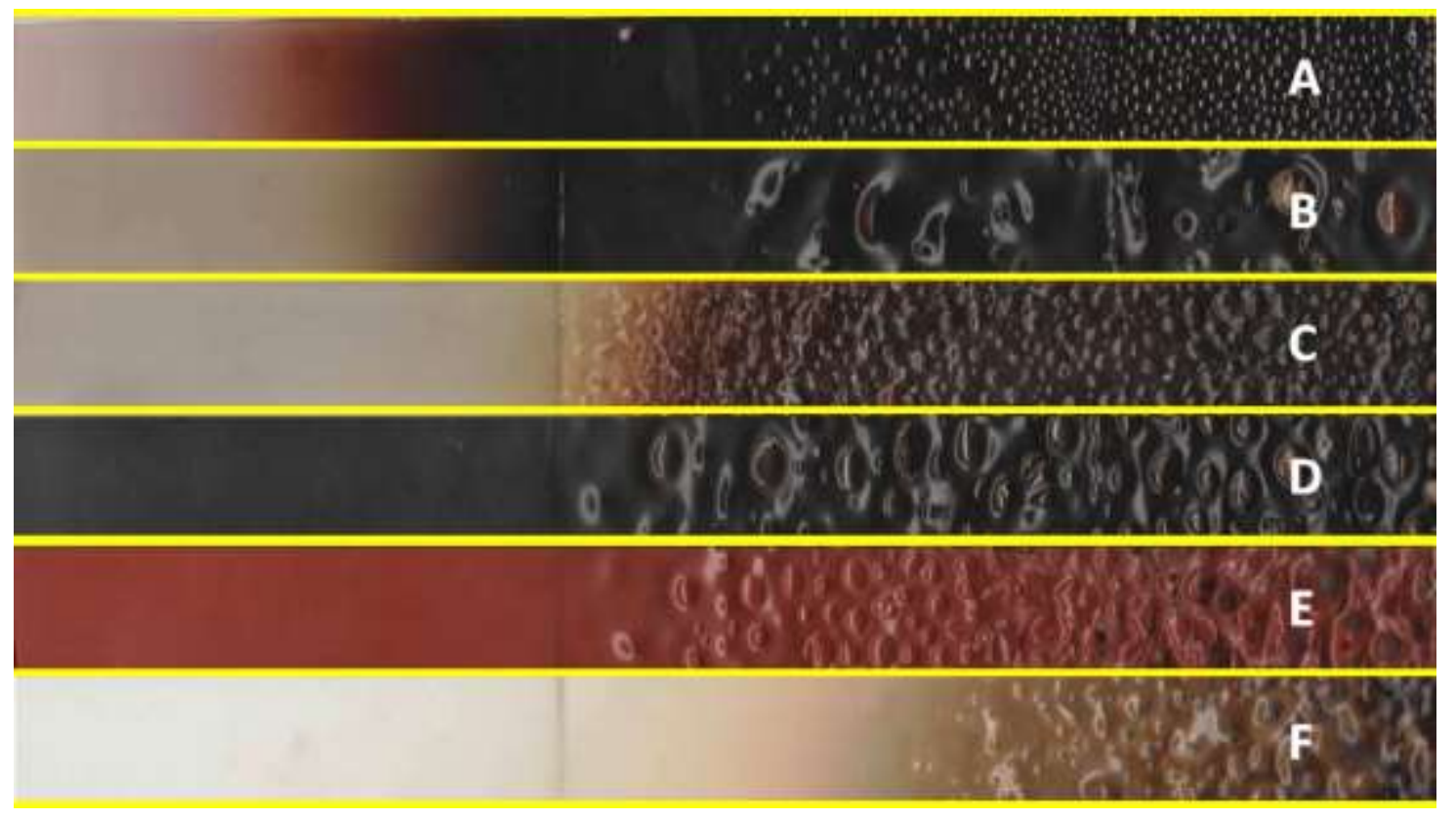

Figure 7. Metrastat sample appearances. (A) Neat PVC; (B) MgAl-LDH; (C) CaAl-LDH; (D) MgCuAl-LDH; (E) MgFeAL-LDH, and (F) MgZnAl-LDH

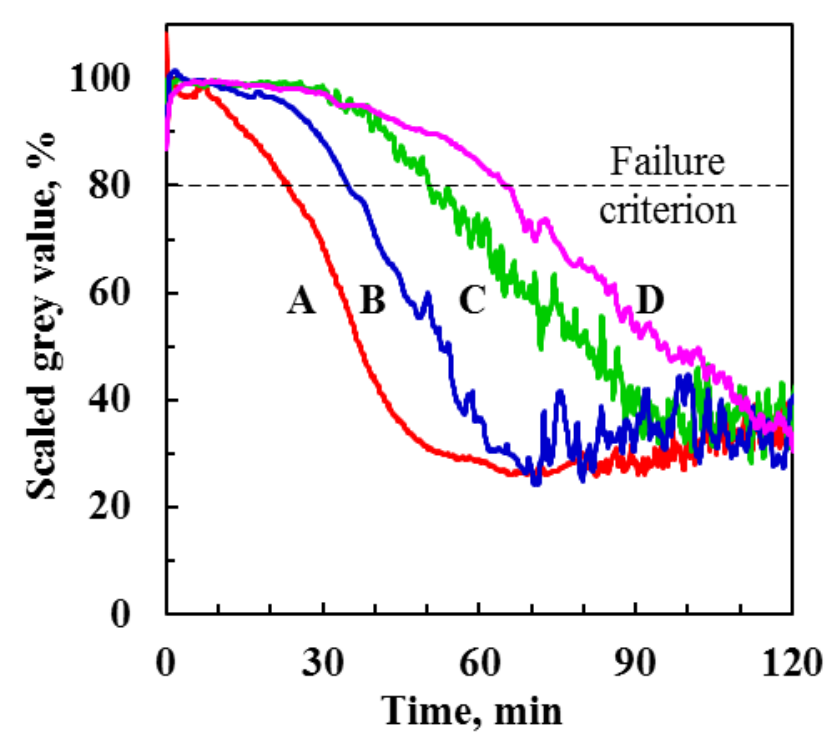

Figure 8. "Normalised" Metrastat grey value test results. (A) Neat PVC; (B) MgAl-LDH; (C) CaAl-LDH; (D) MgZnAl-LDH. The broken horizontal line defines the failure criterion that was adopted.

\subsubsection{Metrastat thermal stability}

The appearance of the flexible PVC after exposure in the Metrastat heat stability oven is shown in Figure 7. The grey scale colour variation along the strips was normalised to 
100 units of the original sheet colour and the results are plotted in Figure 8. An arbitrary failure criterion was defined by a $20 \%$ change in this normalised gray scale. This was used to obtain the heat stability times that are listed in Figure 8 . Unfortunately the original colours of the MgCuAl-LDH and MgFeAl-LDH composites were too dark to allow a reliable assessment. Of the remaining composites, the one based on the MgZnAl-LDH had the highest Metrastat heat stability time $(72 \pm 20 \mathrm{~min})$. The ranking of the additives with respect to the Metrastat heat stability times was (from fastest to slowest degrading):

$$
\text { MgAl-LDH }>\text { MgCuAl-LDH } \approx \mathrm{CaAl}-\mathrm{LDH} \approx \mathrm{MgFeAl}-\mathrm{LDH}>>\mathrm{MgZnAl}-\mathrm{LDH}
$$

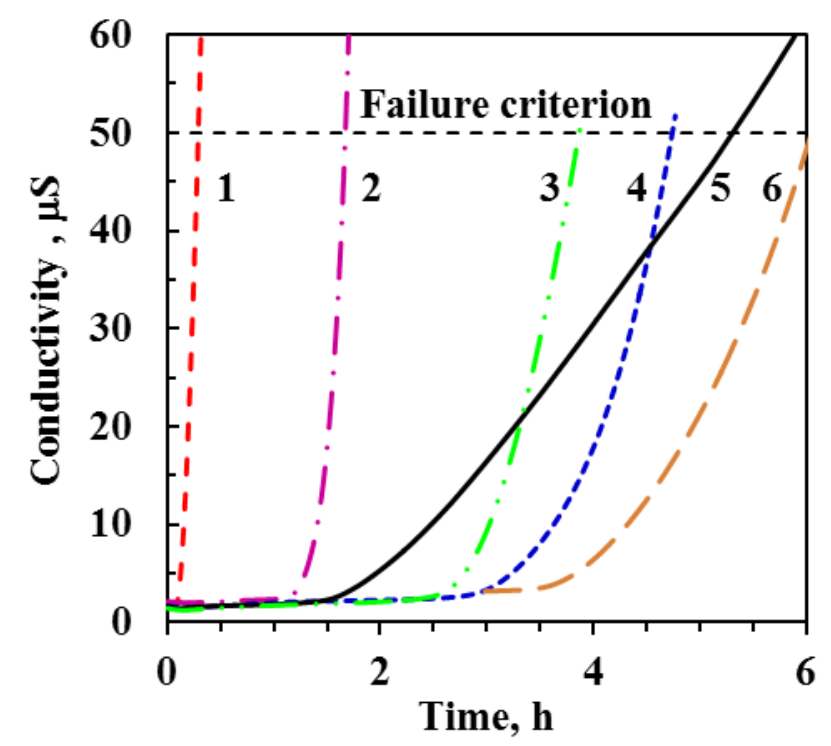

Figure 9. Representative Thermomat conductivity curves for the PVC compounds: 1 . Neat PVC; 2. MgZnAlLDH; 3. MgFeAl-LDH; 4. MgAl-LDH; 5. CaAl-LDH; 6. MgCuAl-LDH. The broken horizontal line defines the failure criterion.

\subsubsection{Thermomat heat stability}

Representative Thermomat conductivity response curves are shown in Figure 9. The induction time corresponds to the onset time while the stability time is defined by the time required to reach a conductivity of $50 \mu \mathrm{S} \mathrm{cm}^{-1}$. Interestingly, while the CaAl-LDH containing 
compound has a lower induction time than the MgAl-LDH compound, it outperformed the latter if the stability time is taken as the failure criterion. The ranking of the stabilisers in terms of the worst to best induction times was as follows:

$$
\text { MgZnAl-LDH >> MgFeAl-LDH > MgAl-LDH > CaAl-LDH > MgCuAl-LDH }
$$

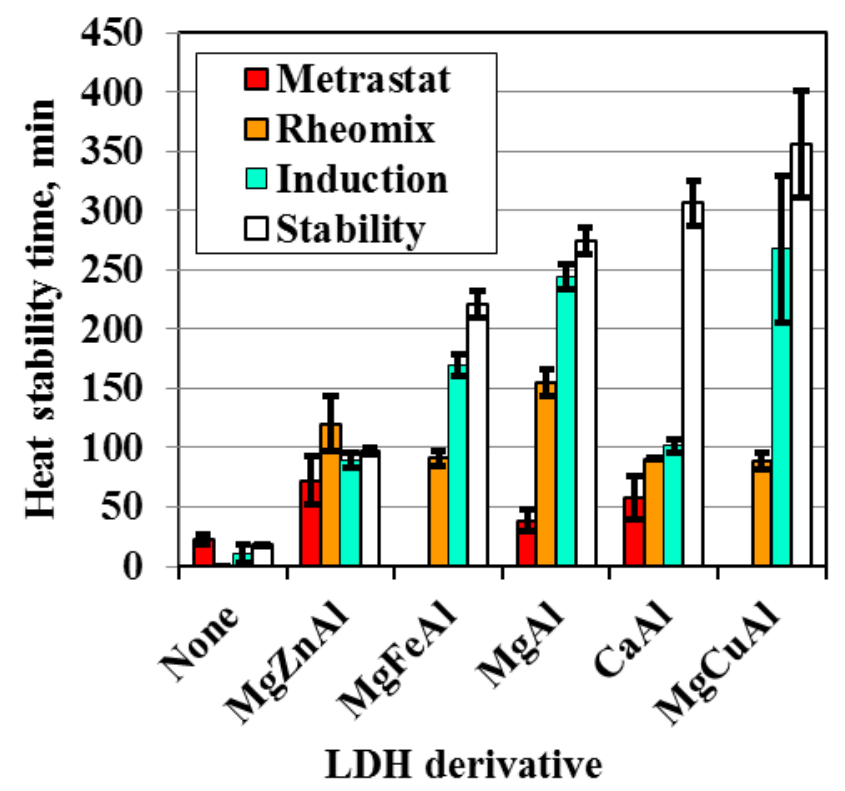

Figure 10. Static and dynamic heat stability times measured at $200{ }^{\circ} \mathrm{C}$ using the torque rheometer technique (Rheomix); following the development of colour with heating time (Metrastat), and tracking the evolution of hydrochloric acid (Thermomat induction and stability times).

The effect of the LDH derivatives on the Thermomat stability times of the flexible PVC compounds are shown in the Figure 10. The neat PVC compound had a stability time of $0.31 \pm 0.01 \mathrm{~h}$. All the $\mathrm{LDH}$ derivatives improved the stability time with $\mathrm{MgCuAl}-\mathrm{LDH}$ giving the best result of $5.93 \pm 0.76 \mathrm{~h}$. As expected from the TGA results, the stability time improvement was least for MgZnAl-LDH. The ranking of the stabiliser stability times from worst to best was as follows:

$$
\text { MgZnAl-LDH > MgFeAl-LDH }>\text { MgAl-LDH }>\text { CaAl-LDH }>\text { MgCuAl-LDH }
$$


This differs from that found for the acceleration of the initial TGA mass loss and also with respect to the Thermomat induction times. The ranking of the CaAl-LDH system has improved to second best.

\section{Discussion}

The SEM, FTIR, XRD and TGA data for the CalAl-LDH compound appeared odd. The FTIR spectrum (Figure 3) indicates the presence of two different carbonate ion containing compounds. The SEM micrograph (Figure 1) shows large flat flakes with smaller crystals located between them. This also suggests the presence of two different phases. The TGA mass loss curve in Figure 4 also looks very different from that usually seen for LDHs. Inspection of the TGA data initially led to the suspicion that the sample might have been contaminated with calcium carbonate. However, with respect to the XRD diffractogram there is no match with calcite or any other calcium carbonate phase in Figure 2. In fact it indicates that the product is a "pure" crystalline phase. The d-spacing calculated for the compound shown in Figure 2 is $0.755 \mathrm{~nm}$ and this matches that reported for the compound calcium monocarboaluminate perfectly $[21,22]$. The structure of this compound is that of a "pure" CaAl-LDH and the formula is: $\left[\mathrm{Ca}_{4} \mathrm{Al}_{2}(\mathrm{OH})_{12}\right] \mathrm{CO}_{3} \cdot 5 \mathrm{H}_{2} \mathrm{O}$.

However, there is another compound called calcium hemicarboaluminate [17] with the structural formula: $\left[\mathrm{Ca}_{4} \mathrm{Al}_{2}(\mathrm{OH})_{12}\right] \mathrm{OH}\left(\mathrm{CO}_{3}\right)_{0.5} \cdot 4 \mathrm{H}_{2} \mathrm{O}$ in which half the interlayer carbonate ions are substituted by hydroxyl ions. Cement curing studies revealed that this hemicarboaluminate forms during the early stages of hydration and as the hydration progresses, a gradual conversion of the hemicarboaluminate into the monocarboaluminate occurs [27]. The conundrum is resolved if one accepts that the present CaAl-LDH sample is actually a mixture of about equal amounts of calcium monocarboaluminate and calcium hemicarboaluminate. Basically the carbonate ions in the latter compound will have slightly 
different electronic environments owing to the presence of the hydroxyl groups. This explains the presence of two carbonate ion absorption bands in the FTIR spectrum. Finally, these two compounds may be expected to have virtually identical XRD diffractograms.

These heat stability results were quite surprising, especially those for the LDH materials containing iron and copper. It is well known that transition metal oxides (especially those of $\mathrm{Fe}$ and $\mathrm{Cu}$ ) promote the degradation of PVC composites [28-30]. At the cost of thermal stability, they reduce the fire risk posed by PVC by increasing char yield and reducing smoke production during fire situations [29]. The present results indicate that the effect of the transition metals on thermal stability of PVC is changed when it they were incorporated into the LDH lattice.

The actual PVC degradation and stabilisation processes occur via multiple primitive reaction steps, each with their own characteristic temperature-dependent rate constant. In addition, mass transfer effects play a significant role. Thus the exact mechanisms are possibly too complicated to be mathematically tractable. Malík and Kröhnke [31] declared: "Present theoretical understanding of polymer degradation and stabilisation principles does not yet sufficiently cover the full chemical and physical complexity of polymer stabilisation ...' Thus, for simplicity and convenience such systems are frequently modelled using the socalled single step reaction approximation $[32,33]$. It is assumed that the process can be described by an apparent first order differential equation analogous to the kinetic expression for a single homogeneous chemical reaction $[33,34]$. Obviously such an equation would in fact apply when the overall kinetics is chemically controlled by a single primitive reaction, e.g. stabiliser consumption during the induction period [35]. A central feature of PVC degradation is its autocatalytic nature [9, 10]. This implies that an autocatalytic reaction mechanism, e.g. the general form suggested by Kamal and Sourour [36] could be considered: $\frac{d \alpha}{d t}=k \alpha^{m}(1-\alpha)^{n}$ 
where $\alpha$ is the degree of conversion that defines the extent of degradation of the polymer [-]: $t$ is the time $[\mathrm{s}] ; k$ is the rate constant $\left[\mathrm{s}^{-1}\right]$ and $m[-], n[-]$ are dimensionless constants defining the reaction orders. A modification that reduces the number of parameters to two is obtained by setting $m=1-1 / \theta$ and $n=1+1 / \theta$ with $\theta \geq 1$. Equation (1) then reduces to:

$\frac{d \alpha}{d t}=k \alpha^{1-1 / \theta}(1-\alpha)^{1+1 / \theta}$

Note that this equation provides a parametric interpolation formula between the predictions of the logistic equation $(\theta \rightarrow \infty)$ describing classic autocatalytic behaviour and second order kinetics $(\theta=1)$. The general solution for isothermal conditions is

$\left(\frac{\alpha}{1-\alpha}\right)^{1 / \theta}=1+\frac{k}{\theta}\left(t-t_{\mathrm{I}}\right)$

where $t_{\mathrm{I}}$ serves as an integration constant with units of time. The degree of conversion can be expressed explicitly as a function of time:

$\alpha=1-\frac{1}{1+\left[1+(k / \theta)\left(t-t_{\mathrm{I}}\right)\right]^{\theta}}$

For $\theta \rightarrow \infty$ Equation (4) reduces to the familiar Proud-Tompkins kinetic expression [37]. For $1 \leq \theta<\infty$ it is possible to enforce the initial condition $\alpha=0$ at $t=0$ by setting $t_{\mathrm{I}}=\theta / \mathrm{k}$. With this condition the equation simplifies to

$\alpha=1-\left[1+(t / \tau)^{\theta}\right]^{-1}$

This equation predicts a rate maximum at a time equal to $[\theta / k][(\theta-1) / \theta+1]^{1 / \theta}$. This means that the S-shaped conversion curve shifts to higher times with increasing $\theta$ and decrease in the rate constant $k$. Note that the apparent reaction rate constant can be calculated from $k=\theta / \tau$. It was assumed that the conductivity is directly proportional to the degree of degradation of the polymer sample. The parameters $\tau$ and $\theta$ were obtained by least squares 
fitting of Equation (5) to the Thermomat conductivity vs. time curves. Typical fits are shown in Figure 11.

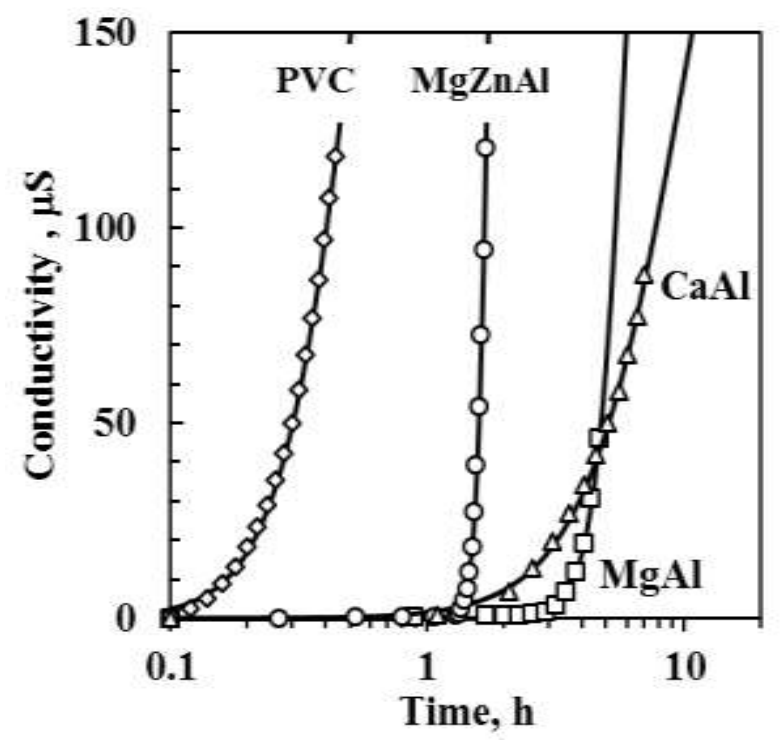

Figure 11. Thermomat conductivity curves showing typical curve fits of equation (5).

Figure 12 shows a plot of the rate constant $k v s$. the reaction order parameter $\theta$. The order parameter for the neat PVC was $\theta=2.92 \pm 0.12$ and the degradation rate constant was $k=5.07 \pm 0.26 \mathrm{~h}$. Except for MgZnAl-LDH, the incorporation of the LDH stabilisers lowered the degradation rate constant. The reaction order parameter for the CaAl-LDH was lower $(2.53 \pm 0.27)$ while for all the other LDH-based compounds it was higher. Interestingly and rather unexpectedly, these two parameters appeared to be strongly correlated for the LDHstabilised PVC compounds. In fact, the relationship can be expressed by $k \approx 0.196 \mathrm{e}^{\theta / 4}$. This shows that the rate constant $k$ increases rapidly with increase in the reaction order parameter $\theta$. As mentioned above, autocatalytic behaviour is indicated by large values of order the parameter $\theta$. This means that, with the exception of the CaAl-LDH, the presence of the LDH stabilisers emphasised the autocatalytic nature of the degradation process. With exception of 
the MgZnAl-LDH, the presence of the LDH stabilisers significantly lowered the magnitude of the reaction rate constant $k$.

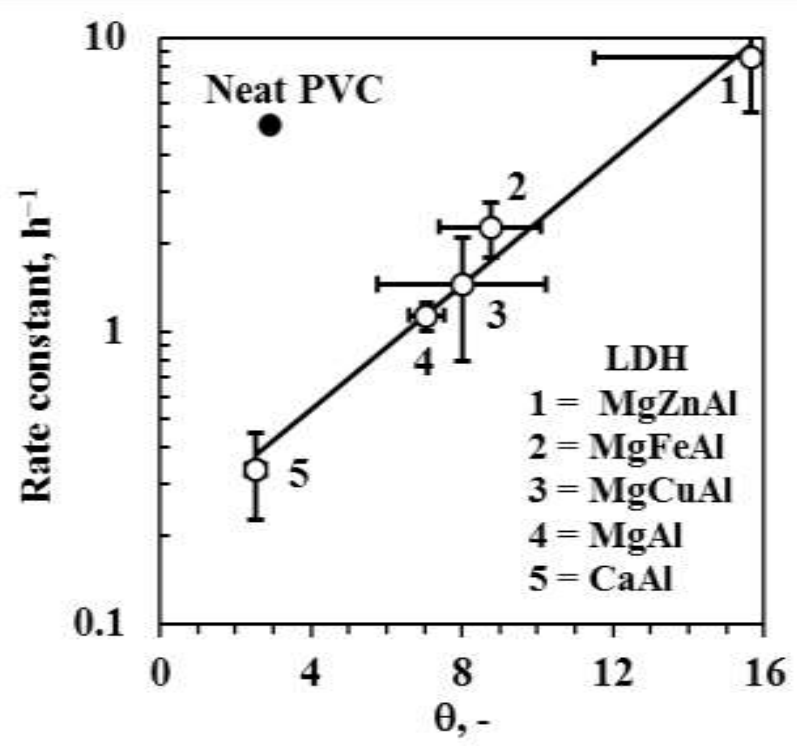

Figure 12. The correlation between the parameters of equation (5) for the LDH-stabilised PVC compounds. The solid line is described by the relation $k=0.196 \mathrm{e}^{\theta / 4}$.

\section{Conclusion}

Layered double hydroxides (LDHs) derivatives were synthesised using a hydrothermal method. Apart from the conventional LDH used as heat stabiliser for PVC

$\left.\left[\mathrm{Mg}_{4} \mathrm{Al}_{2}(\mathrm{OH})_{12}\right] \mathrm{CO}_{3} .4 \mathrm{H}_{2} \mathrm{O}\right)$ the synthesis efforts targeted the following compounds:

$\left[\mathrm{Mg}_{3} \mathrm{ZnAl}_{2}(\mathrm{OH})_{12}\right] \mathrm{CO}_{3} .4 \mathrm{H}_{2} \mathrm{O} ;\left[\mathrm{Mg}_{3} \mathrm{CuAl}_{2}(\mathrm{OH})_{12}\right\} \mathrm{CO}_{3} \cdot 4 \mathrm{H}_{2} \mathrm{O} ;\left[\mathrm{Mg}_{4} \mathrm{AlFe}(\mathrm{OH})_{12}\right] \mathrm{CO}_{3} .4 \mathrm{H}_{2} \mathrm{O}$, and $\left[\mathrm{Ca}_{4} \mathrm{Al}_{2}(\mathrm{OH})_{12}\right] \mathrm{CO}_{3} .5 \mathrm{H}_{2} \mathrm{O}$. Characterisation using XRD, ICP-MS and FTIR confirmed that the products approached these idealised compositions. The exception was the calcium based LDH (calcium hemicarboaluminate). This product turned out to be a mixture of the target compound and calcium hemicarboaluminate with the structural formula:

$\left[\mathrm{Ca}_{4} \mathrm{Al}_{2}(\mathrm{OH})_{12}\right] \mathrm{OH}\left(\mathrm{CO}_{3}\right)_{0.5} \cdot 4 \mathrm{H}_{2} \mathrm{O}$.

It was found that the best performance in dynamic heat stability tests was achieved with the conventional product $\left[\mathrm{Mg}_{4} \mathrm{Al}_{2}(\mathrm{OH})_{12}\right] \mathrm{CO}_{3} \cdot 4 \mathrm{H}_{2} \mathrm{O}$. However, $\left[\mathrm{Mg}_{3} \mathrm{ZnAl}_{2}(\mathrm{OH})_{12}\right] \mathrm{CO}_{3} \cdot 4 \mathrm{H}_{2} \mathrm{O}$ 
improved colour retention in Metrastat static heat stability tests. In addition,

$\left[\mathrm{Mg}_{3} \mathrm{CuAl}_{2}(\mathrm{OH})_{12}\right] \mathrm{CO}_{3} .4 \mathrm{H}_{2} \mathrm{O}$ performed better as a $\mathrm{HCl}$ scavenger, preventing the release of hydrochloric acid for a longer time in the Thermomat evaluation. The key finding of this study is that different metal substitutions affect performance differently in different heat stability tests. This means that there should be room for fine tuning of LDH heat stabilisers for optimal performance in specific tests and end-use applications.

\section{Acknowledgements}

Financial support from the THRIP programme of the Department of Trade and Industry and the National Research Foundation as well as Greenfield Innovation is gratefully acknowledgement.

\section{References}

[1] Leroux F, Besse J-P. Polymer Interleaved Layered Double Hydroxide: A New Emerging Class of Nanocomposites. Chemistry of Materials. 2001;13:3507-15.

[2] Rives V. Layered Double Hydroxides: Present and Future: Nova Science Publishers; 2001.

[3] Cavani F, Trifirò F, Vaccari A. Hydrotalcite-type anionic clays: Preparation, properties and applications. Catalysis Today. 1991;11:173-301.

[4] Khan AI, O'Hare D. Intercalation chemistry of layered double hydroxides: recent developments and applications. Journal of Materials Chemistry. 2002;12:3191-8.

[5] Miyata S, Kumura T. Synthesis of new hydrotalcite-like compounds and their physicochemical properties. Chemistry Letters. 1973:843-8.

[6] Ulibarri M, Pavlovic I, Barriga C, Hermosin M, Cornejo J. Adsorption of anionic species on hydrotalcite-like compounds: effect of interlayer anion and crystallinity. Applied Clay Science. 2001;18:17-27.

[7] Taylor H. Crystal structures of some double hydroxide minerals. Mineral Mag. 1973;39:377-89.

[8] Braun D. Poly(vinyl chloride) on the Way from the 19th Century to the 21st Century. Journal of Polymer Science, Part A: Polymer Chemistry. 2004;42:578-86.

[9] Starnes Jr WH. Structural and mechanistic aspects of the thermal degradation of poly(vinyl chloride). Progress in Polymer Science (Oxford). 2002;27:2133-70.

[10] Starnes Jr WH, Ge X. Mechanism of autocatalysis in the thermal dehydrochlorination of poly(vinyl chloride). Macromolecules. 2004;37:352-9.

[11] Loffeld P. Novel Synthetic Hydrotalcites for Applications in Polymer Science:

Universiteit Utrecht, Faculteit Scheikunde; 2004. 
[12] Lin Y-J, Li D-Q, Evans DG, Duan X. Modulating effect of Mg-Al-CO3 layered double hydroxides on the thermal stability of PVC resin. Polymer Degradation and Stability. 2005;88:286-93.

[13] van der Ven L, van Gemert MLM, Batenburg LF, Keern JJ, Gielgens LH, Koster TPM, et al. On the action of hydrotalcite-like clay materials as stabilizers in polyvinylchloride. Applied Clay Science. 2000;17:25-34.

[14] Lin Y, Wang J, Evans DG, Li D. Layered and intercalated hydrotalcite-like materials as thermal stabilizers in PVC resin. Journal of Physics and Chemistry of Solids. 2006;67:9981001 .

[15] Bacaloglu R, Stewen U. Study of PVC degradation using a fast computer scanning procedure. Journal of Vinyl and Additive Technology. 2001;7:149-55.

[16] Labuschagné FJWJ, Giesekke, E.W., Van Schalkwyk, J.D. . Production of Hydrotalcite. South Africa2007.

[17] Runčevski T, Dinnebier RE, Magdysyuk OV, Pöllmann H. Crystal structures of calcium hemicarboaluminate and carbonated calcium hemicarboaluminate from synchrotron powder diffraction data. Acta Crystallographica Section B: Structural Science. 2012;68:493-500.

[18] Pukánszky B, Nagy TT, Kelen T, Tüdõs F. Comparison of dynamic and static degradation of poly(vinyl chloride). Journal of Applied Polymer Science. 1982;27:2615-23.

[19] Collins EA, Metzger AP, Furgason RR. Relationship between torque and capillary rheometer thermal stability measurements for PVC compounds. Polymer Engineering \& Science. 1976;16:240-5.

[20] Collins EA, Krier CA. Poly(vinyl chloride) thermal stability. I. Evaluation by melt rheology. Journal of Applied Polymer Science. 1966;10:1573-89.

[21] François M, Renaudin G, Evrard O. A cementitious compound with composition 3CaO.A12O3-CaCO3.11H2O. Acta Crystallographica Section C: Crystal Structure Communications. 1998;54:1214-7.

[22] Renaudin G, Francois M, Evrard O. Order and disorder in the lamellar hydrated tetracalcium monocarboaluminate compound. Cement and Concrete Research. 1999;29:63-9. [23] Reichle WT. Catalytic reactions by thermally activated, synthetic, anionic clay minerals. Journal of Catalysis. 1985;94:547-57.

[24] Moyo L, Focke WW, Heidenreich D, Labuschagne F, Radusch H-J. Properties of layered double hydroxide micro-and nanocomposites. Materials Research Bulletin. 2013;48:1218-27.

[25] Frost RL, Martens W, Ding Z, Kloprogge JT. DSC and high-resolution TG of synthesized hydrotalcites of $\mathrm{Mg}$ and $\mathrm{Zn}$. Journal of Thermal Analysis and Calorimetry. 2003;71:429-38.

[26] Levchik SV, Weil ED. Overview of the recent literature on flame retardancy and smoke suppression in PVC. Polymers for Advanced Technologies. 2005;16:707-16.

[27] Ipavec A, Gabrovšek R, Vuk T, Kaučič V, MačEk J, Meden A. Carboaluminate phases formation during the hydration of calcite-containing Portland cement. Journal of the American Ceramic Society. 2011;94:1238-42.

[28] Gupta MC, Viswanath SG. Role of metal oxides in the thermal degradation of poly(vinyl chloride). Industrial and Engineering Chemistry Research. 1998;37:2707-12.

[29] Li B. Study of thermal degradation and decomposition of rigid poly(vinyl chloride) with metal oxides using thermogravimetry and cone calorimetry. Polymer Degradation and Stability. 2000;68:197-204.

[30] Blazsó M, Jakab E. Effect of metals, metal oxides, and carboxylates on the thermal decomposition processes of poly(vinyl chloride). Journal of Analytical and Applied Pyrolysis. 1999;49:125-43. 
[31] Malík J, Kröhnke C. Polymer stabilization: present status and possible future trends. Comptes Rendus Chimie. 2006;9:1330-7.

[32] Simon P. Considerations on the single-step kinetics approximation. Journal of Thermal Analysis and Calorimetry. 2005;82:651-7.

[33] Dente M, Bozzano G, Faravelli T, Marongiu A, Pierucci S, Ranzi E. Kinetic Modelling of Pyrolysis Processes in Gas and Condensed Phase. In: Guy BM, editor. Advances in Chemical Engineering: Academic Press; 2007. p. 51-166.

[34] Anderson HL, Kemmler A, Höhne GWH, Heldt K, Strey R. Round robin test on the kinetic evaluation of a complex solid state reaction from 13 European laboratories. Part 1. Kinetic TG-analysis. Thermochimica Acta. 1999;332:33-53.

[35] Pospíšil J, Horák Z, Pilař J, Billingham NC, Zweifel H, Nešpůrek S. Influence of testing conditions on the performance and durability of polymer stabilisers in thermal oxidation.

Polymer Degradation and Stability. 2003;82:145-62.

[36] Kamal MR, Sourour S. Kinetics and thermal characterization of thermoset cure. Polymer Engineering \& Science. 1973;13:59-64.

[37] Brown ME. The Prout-Tompkins rate equation in solid-state kinetics. Thermochimica Acta. 1997;300:93-106. 